Article

\title{
Immune Response of Eastern Honeybee Worker to Nosema ceranae Infection Revealed by Transcriptomic Investigation
}

\author{
Wenhao Xing ${ }^{1,+}{ }^{+}$, Dingding Zhou ${ }^{2,+}$, Qi Long ${ }^{2}{ }^{\mathbb{D}}$, Minghui Sun ${ }^{2}$, Rui Guo ${ }^{2,3, *}$ and Limei Wang ${ }^{4}$ \\ 1 College of Animal Science, Guizhou University, Guiyang 550025, China; xingwenhao2021@126.com \\ 2 College of Animal Sciences (College of Bee Science), Fujian Agriculture and Forestry University, \\ Fuzhou 350002, China; zdd03569981@163.com (D.Z.); 11070190695@126.com (Q.L.); hnmhsun@126.com (M.S.) \\ 3 Apitherapy Research Institute, Fujian Agriculture and Forestry University, Fuzhou 350002, China \\ 4 Dongying Vocational Institute, Dongying 257000, China; wlm11@163.com \\ * Correspondence: ruiguo@fafu.edu.cn; Tel./Fax: +86-0591-8764-0197 \\ + These authors contributed equally to this work.
}

Citation: Xing, W.; Zhou, D.; Long,

Q.; Sun, M.; Guo, R.; Wang, L.

Immune Response of Eastern

Honeybee Worker to Nosema ceranae Infection Revealed by Transcriptomic Investigation. Insects 2021, 12, 728. https://doi.org/10.3390/

insects 12080728

Academic Editor: Elke Genersch

Received: 14 June 2021

Accepted: 5 August 2021

Published: 14 August 2021

Publisher's Note: MDPI stays neutral with regard to jurisdictional claims in published maps and institutional affiliations.

Copyright: (c) 2021 by the authors. Licensee MDPI, Basel, Switzerland. This article is an open access article distributed under the terms and conditions of the Creative Commons Attribution (CC BY) license (https:// creativecommons.org/licenses/by/ $4.0 /)$.
Simple Summary: Currently, knowledge regarding Apis cerana-Nosema ceranae interaction is very limited, though A. cerana is the original host of N. ceranae. Apis cerana cerana is a subspecies of A. cerana and a major bee species used in the beekeeping industry in China and other countries. Here, the effective infection of $A$. c. cerana workers by N. ceranae was verified, followed by transcriptomic investigation of host responses. Furthermore, immune responses between A. c. cerana and Apis mellifera ligustica were deeply compared and discussed. In total, 1127 and 957 N. ceranae-responsive genes were identified in the infected midguts at $7 \mathrm{~d}$ post-inoculation (dpi) and $10 \mathrm{dpi}$, respectively. Additionally, DEGs in workers' midguts at both $7 \mathrm{dpi}$ and $10 \mathrm{dpi}$ were associated with six cellular immune pathways and three humoral immune pathways. Noticeably, one up-regulated gene was enriched in the NF- $\kappa$ B signaling pathway in the midgut at 10 dpi. Further analysis indicated that different cellular and humoral immune responses were employed by A. c. cerana and A. m. ligustica workers to combat $N$. ceranae. Our findings provide a foundation for clarifying the mechanisms regulating the immune response of $A$. c. cerana workers to $N$. ceranae invasion and developing new approaches to control bee microsporidiosis.

Abstract: Here, a comparative transcriptome investigation was conducted based on high-quality deep sequencing data from the midguts of Apis cerana cerana workers at $7 \mathrm{~d}$ post-inoculation (dpi) and $10 \mathrm{dpi}$ with Nosema ceranae and corresponding un-inoculated midguts. PCR identification and microscopic observation of paraffin sections confirmed the effective infection of $A$. c. cerana worker by $N$. ceranae. In total, 1127 and 957 N. ceranae-responsive genes were identified in the infected midguts at $7 \mathrm{dpi}$ and $10 \mathrm{dpi}$, respectively. RT-qPCR results validated the reliability of our transcriptome data. GO categorization indicated the differentially expressed genes (DEGs) were respectively engaged in 34 and 33 functional terms associated with biological processes, cellular components, and molecular functions. Additionally, KEGG pathway enrichment analysis showed that DEGs at 7 dpi and 10 dpi could be enriched in 231 and 226 pathways, respectively. Moreover, DEGs in workers' midguts at both $7 \mathrm{dpi}$ and $10 \mathrm{dpi}$ were involved in six cellular immune pathways such as autophagy and phagosome and three humoral immune pathways such as the Toll/Imd signaling pathway and Jak-STAT signaling pathway. In addition, one up-regulated gene (XM_017055397.1) was enriched in the NF- $\kappa$ B signaling pathway in the workers' midgut at 10 dpi. Further investigation suggested the majority of these DEGs were engaged in only one immune pathway, while a small number of DEGs were simultaneously involved in two immune pathways. These results together demonstrated that the overall gene expression profile in host midgut was altered by N. ceranae infection and some of the host immune pathways were induced to activation during fungal infection, whereas some others were suppressed via host-pathogen interaction. Our findings offer a basis for clarification of the mechanism underlying the immune response of $A$. c. cerana workers to N. ceranae infection, but also provide novel insights into eastern honeybee-microsporodian interaction. 


\section{Introduction}

Honeybees are a pivotal pollinator for a great number of wild plants and crops throughout the world [1]. In addition, honeybees are widely used as a model for investigating caste differentiation [2], social behavior [3], disease transmission [4], epigenomics [5], gene regulation [6], and recently, transgenic manipulation [7] and gene editing [8].

However, as a eusocial insect, honeybees are vulnerable to infection by many pathogens and parasites. Among them, Nosema ceranae is a spore-forming unicellular and obligate intracellular fungal parasite that exclusively infects the midgut epithelium cells and not all epithelial cells of the adult honeybee, leading to bee microsporidiosis $[9,10]$. N. ceranae was first identified in 1996 in colonies of the Asian honeybee, Apis cerana [11]. Evidently, it switched hosts from A. cerana to Apis mellifera some decades ago and spread to western honeybee colonies throughout the world [12]. Currently, N. ceranae is the predominant microsporidian infecting bees with a worldwide distribution $[13,14]$. N. ceranae infection has been suggested to affect the health of honeybee hosts via disturbance of hormones [15], reduction of lifespan [16], degeneration of midgut epithelial cells [17], energetic stress [18], cell apoptosis inhibition [19-21], and immunity suppression [22,23].

Honeybees have developed various defense mechanisms against parasitic infection, including cellular and humoral immune responses [24]. The honeybee humoral response has been shown to involve four antimicrobial peptides: abaecin, apidaecin, defensin, and hymenoptaecin [25]. In the past decade, the impact of $N$. ceranae on immune defense of the western honeybee has been widely studied $[15,23,26-29]$. Our group previously performed next-generation sequencing and transcriptome analysis of Apis mellifera ligustica workers' midguts infected by N. ceranae, and found that both cellular and humoral immune responses were activated during the early infection stage, that the former may play a major role in defense against fungal infection, and that host cellular immune response was increasingly enhanced during the late stage of infection while the humoral immune response weakened significantly [30]. Meanwhile, we revealed the mechanism underlying $N$. ceranae infection of $A$. m. ligustica workers by analyzing the differential expression profile of fungal genes [31].

A. cerana is endemic to Asia and has been used for commercial beekeeping and pollination over thousands of years [32]. A. cerana differs from A. mellifera in distinct biological characteristics, including longer flight duration [33], effective grooming and hygienic behaviors [34], adaptation to extreme weather conditions [35], lower production rate of royal jelly [36], and cooperative group-level defenses [37]. The reference genome of A. cerana was published in 2015; it allows deep investigation of the eastern honeybee's biology including immunity and development. Currently, study on A. cerana-N. ceranae interaction has lagged significantly, although A. cerana is the primary host of N. ceranae. Compared to the western honeybee, knowledge of the eastern honeybee's immune response to $N$. ceranae invasion is very limited.

To analyze the cellular and humoral immune responses of $A$. c. cerana workers to $N$. ceranae infection, comparative transcriptome investigation was conducted in this work based on previously obtained high-quality deep sequencing data from midguts of A. c. cerana workers at $7 \mathrm{~d}$ post inoculation (dpi) and $10 \mathrm{dpi}$ with $N$. ceranae and corresponding un-inoculated midguts. Findings from our study not only offer a foundation for clarification of the molecular mechanism regulating the immune response of A.c. cerana workers to $N$. ceranae infection, but also provide novel insights into eastern honeybeemicrosporidian interaction during bee nosemosis. 


\section{Materials and Methods}

\subsection{Transcriptome Data Source}

Three N. ceranae-free colonies of A. c. cerana located in the teaching apiary of the College of Animal Sciences (College of Bee Science) in Fujian Agriculture and Forestry University were selected for the present study. Before and during the whole experiment, no Varroa was detected. RT-PCR was performed to examine the prevalence of two bee microsporidia (N. ceranae and Nosema apis) and seven common bee viruses (ABPV, BQCV, $\mathrm{CBPV}, \mathrm{DWV}, \mathrm{KBV}, \mathrm{IAPV}$, and SBV) in the newly emergent $A$. c. cerana workers using previously developed specific primers (Table S1) [38-44]. Agarose gel electrophoresis (AGE) showed that no signal bands were amplified from the above-mentioned two microsporidia and seven viruses (Figure S1).

A. c. cerana workers' midguts inoculated with $N$. ceranae and corresponding uninoculated midguts were prepared as described previously [45]. Briefly, (1) the midguts of 50 infected workers from one colony located in Yuan'an apiary in Fuzhou city were removed and crushed in sterile water and filtered with four layers of gauze, centrifuged at $6000 \times g$ for $5 \mathrm{~min}$, and then purified on a discontinuous Percoll gradient; a small quantity of spores were identified and verified to be mono-specific using PCR with previously developed primers (F: CGGATAAAAGAGTCCGTTACC; R: TGAGCAGGGTTCTAGGGAT) [39], followed by measurement of spore concentration with a CL kurt counter (JIMBIO). (2) Newly emerged Nosema-free workers were carefully removed from frames from three A.c. cerana colonies, kept in plastic cages in groups of 30, and reared in an incubator at $34 \pm 2{ }^{\circ} \mathrm{C}$ for $24 \mathrm{~h}$ after eclosion. The workers in N. ceranae-treated groups $(n=3)$ were starved for $2 \mathrm{~h}$, and then each was fed $5 \mu \mathrm{L}$ of a $50 \%$ sucrose ( $w / v$ in sterile water) solution containing $1 \times 10^{6} \mathrm{~N}$. ceranae spores [46], whereas workers in control groups $(n=3)$ were each fed $5 \mu \mathrm{L}$ of a $50 \%$ sucrose solution without fungal spores; workers that did not consume the entire droplet were discarded. The workers were fed ad libitum with a solution of sucrose $(50 \% w / w)$ for $24 \mathrm{~h}$ after inoculation, and the feeders were replaced daily throughout the whole experiment. Each cage was checked every $24 \mathrm{~h}$, and dead bees were removed. (3) Nine workers from each cage in the N. ceranae-treated and control groups were sacrificed at $7 \mathrm{~d}$ post-inoculation (dpi) and $10 \mathrm{dpi}$, followed by dissection and separation of the midgut samples, which were immediately pooled and frozen in liquid nitrogen.

Total RNA extraction, cDNA library construction, and strand-specific cDNA librarybased RNA-seq of the midgut samples were conducted as previously described [47]. In brief, total RNA of the aforementioned 12 midgut samples was respectively isolated using Trizol (Life Technologies) and detected using 1\% AGE. After removal of rRNAs, mRNAs were fragmented into short fragments using fragmentation buffer (Illumina) and then reverse-transcribed into cDNA with random primers. Second-strand cDNA was synthesized and then purified, end repaired, poly (A) added, and ligated to Illumina sequencing adapters, followed by digestion of the second-strand cDNA. The digested products were size selected by AGE, PCR amplified, and sequenced on illumina HiSeq ${ }^{\mathrm{TM}}$ 4000 system (illumine, San Diego, CA, USA) by Guangzhou Gene Denovo Biotechnology Co. We used AcCK1-1, AcCK1-2, and AcCK1-3 as three replicate libraries for midgut samples at 7 dpi in control groups, AcT1-1, AcT1-2, and AcT1-3 as three replicate libraries for midgut samples at $7 \mathrm{dpi}$ in N. ceranae-treated groups, AcCK2-1, AcCK2-2, and AcCK2-3 as three replicate libraries for midgut samples at 10 dpi in control groups, and AcT2-1, AcT2-2, and AcT2-3 as three replicate libraries for midgut samples at 10 dpi in N. ceranaetreated groups.

Quality control of the generated raw reads and mapping of the clean reads were previously performed [45] according to the method described by Chen et al. [47]. In short, raw reads were filtered to gain clean reads with high quality by removing reads containing adapters, more than $10 \%$ of unknown nucleotides $(\mathrm{N})$, and more than $50 \%$ of low quality ( $q$ value $\leq 20$ ) bases, which were then aligned to the ribosome RNA (rRNA) database (www.arb-silva.de/) (20 March 2021) with Bowtie2 [48]. Next, the rRNA-removed clean reads of each group were aligned to the A. cerana reference genome (assembly ACSNU-2.0) 
utilizing TopHat2 [49], and the mapped clean reads were then used for downstream analyses. The result of quality control demonstrated that $124,216,829,174,700,032,99,030,788$, and 205,297,946 raw reads were produced from AcCK1, AcT1, AcCK2, and AcT2 groups, and $121,949,977,171,868,061,97,432,267$, and 200,570,776 clean reads were obtained after quality control, with Q20 of $94.60 \%, 94.96 \%, 94.91 \%$, and $94.58 \%$, respectively. Additionally, $75,553,033,68,416,248,64,919,402$, and $65,107,760$ clean reads could be mapped to the reference genome of $A$. cerana (assembly ACSNU-2.0); moreover, Pearson correlation coefficient for each group was above 0.87 [44]. Taken together, the high-quality transcriptome data could be used for related analyses in this current work.

\subsection{Confirmation of Effective Infection of Eastern Honeybee Workers by N. ceranae}

Following the above-mentioned procedure, A. c. cerana 1-day-old workers in N. ceranaetreated groups were each artificially inoculated with $1 \times 10^{6} \mathrm{~N}$. ceranae spores. The midguts at $12 \mathrm{dpi}$ in the N. ceranae-treated group and un-treated group were respectively dissected out and fixed using $4 \%$ paraformaldehyde. Paraffin sections were prepared using a microtome (Leica, Nussloch, Germany) and an embedding center (Junjie, Wuhan, China) and then stained with hematoxylin eosin (HE) stain by Shanghai Sangon Biological Engineering Co. Ltd., followed by observation using an optical microscope with digital camera (SOPTOP, Shanghai, China).

Total DNA of workers' midgut at $12 \mathrm{dpi}$ with $N$. ceranae was isolated as PCR template. Clean spores of N. ceranae were set as a positive control. Workers' midgut at $12 \mathrm{dpi}$ without $N$. ceranae was set as a negative control, and sterile water as another negative control. PCR amplification was conducted on a T100 thermo cycler (BIO-RAD) with previously described primers for N. ceranae (F: CGAGCGGTTTCCCATCTCAGTA; R: AAAACACCGGAACTCGTCAGCT) [38] and the following conditions: pre-denaturation step at $94{ }^{\circ} \mathrm{C}$ for $5 \mathrm{~min} ; 37 \mathrm{amplification}$ cycles of denaturation at $94^{\circ} \mathrm{C}$ for $50 \mathrm{~s}$, annealing at $59^{\circ} \mathrm{C}$ for $30 \mathrm{~s}$, and elongation at $72{ }^{\circ} \mathrm{C}$ for $1 \mathrm{~min}$; followed by a final elongation step at $72{ }^{\circ} \mathrm{C}$ for $10 \mathrm{~min}$. The PCR products were examined on 1.5\% AGE with Genecolor (Gene-Bio) staining.

\subsection{Identification and Analysis of DEGs}

The expression level of each transcript was normalized with the fragments per kilobase of transcript per million mapped reads (FPKM) method [45], which could eliminate the influence of different transcript lengths and sequencing data amounts on the calculation of transcript expression. The $p$ value corresponded to differential gene expression at statistically significant levels [50]. DEGs were identified following the standard of $p \leq 0.05$ and absolute value of $\log _{2}$ (fold change) $\geq 1$. Venn analysis was performed to identify the shared up-regulated and down-regulated genes between AcCK1 vs. AcT1 and AcCK2 vs. AcT2 comparison groups based on the OmicShare platform (www.omicshare.com/tools) (6 April 2021).

\subsection{GO Categorization and KEGG Pathway Enrichment Analysis of DEGs}

GO classification of DEGs was conducted using WEGO software [51]. KEGG pathway annotation was performed with Blastall software against the Kyoto Encyclopedia of Genes and Genomes (KEGG) database (http:/ /www.kegg.jp/) (7 April 2021). Pathways with a corrected $p$ value $\leq 0.05$ were designated as significantly enriched pathways for DEGs.

\subsection{Construction and Analysis of Immune-Associated Regulatory Network of DEGs}

On the basis of the results of KEGG pathway enrichment analysis, cellular immune pathways (ubiquitin mediated proteolysis, phagosome, autophagy, lysosome, endocytosis, and melanogenesis) as well as humoral immune pathways (MAPK, Jak-STAT, Toll/Imd, and NF- $\kappa$ B signaling pathways) were selected for construction of a regulatory network following the enrichment relationship between DEGs and the above-mentioned immuneassociated pathways following our previously described method [52]. The regulatory network was then visualized with Cytoscape v3.2.1 (Cytoscape, Bethasda, MD, USA) [53]. 


\subsection{RT-qPCR Validation of DEGs}

To verify the reliability of the transcriptome datasets used in this study, nine DEGs (XM_017062027.1, TCONS_00045707, XM_017062123.1, XM_017064466.1, XM_017057571.1, XM_017050556.1, XM_017063843.1,XM_017048437.1, XM_017051020.1) in AcCK1 vs. AcT1 and nine DEGs (XM_017053873.1, XM_017066488.1, TCONS_00045565, XM_017051020.1, TCONS_00009057, XM_017054185.1, XM_017062504.1,XM_017050756.1, XM_017057504.1) in AcCK2 vs. AcT2 were randomly selected for RT-qPCR. The first cDNA strand was synthesized with the SuperScript first-strand synthesis system (Yeasen) according to the protocol. Primers (shown in Table S1) for qPCR were designed utilizing DNAMAN software and synthesized by Sangon Biotech Co., Ltd. (Shanghai). The housekeeping gene actin was used as an internal control. The RNA samples used as templates for RNA-seq were the same as those used for RT-qPCR, which was conducted on a QuanStudio RealTime PCR System (ThemoFisher, Walthem, MA, USA). The $20 \mu \mathrm{L}$ PCR reaction mixture contained $10 \mu \mathrm{L}$ SYBR Green dye (Yeasen), $1 \mu \mathrm{L}(10 \mu \mathrm{mol} / \mathrm{L})$ specific forward primer, $1 \mu \mathrm{L}$ $(10 \mu \mathrm{mol} / \mathrm{L})$ reverse primer, $1 \mu \mathrm{L}(10 \mathrm{ng} / \mu \mathrm{L})$ diluted cDNA, and $7 \mu \mathrm{L}$ RNase free water. Cycling parameters were as follows: $95{ }^{\circ} \mathrm{C}$ for $1 \mathrm{~min}$, followed by 40 cycles at $95{ }^{\circ} \mathrm{C}$ for $15 \mathrm{~s}, 55^{\circ} \mathrm{C}$ for $30 \mathrm{~s}$, and $72{ }^{\circ} \mathrm{C}$ for $45 \mathrm{~s}$. The relative gene expression was calculated using the $2^{-\Delta \Delta C T}$ method [54]. The experiment was carried out times using three independent biological samples.

\subsection{Statistical Analysis}

All statistical analyses were performed using SPSS software (IBM, Armonk, NY, USA) and GraphPad Prism 6.0 software (GraphPad, San Diego, CA, USA). Data were presented as mean \pm standard deviation (SD). Statistical analysis was performed using independentsamples $t$-test and one-way ANOVA.

\section{Results}

\subsection{Effective Infection of A. c. cerana Worker by N. ceranae}

Microscopic observation of paraffin sections indicated that no spores were present in epithelial cells of un-inoculated workers' midgut (Figure 1A,B), while a number of spores were detected in epithelial cells of workers' midgut at 12 dpi with N. ceranae (Figure 1C,D). Additionally, PCR identification demonstrated that the expected fragment (about 76 bp) could be amplified from $N$. ceranae-inoculated midgut, which was in accordance with that amplified from $N$. ceranae spores, whereas no signal fragment could be amplified from un-inoculated midgut (Figure 1E). Together, these results confirmed the effective infection of A. c. cerana workers by N. ceranae.

\subsection{DEGs Involved in A. c. cerana Workers' Midgut Response to N. ceranae Infection}

In comparison with uninfected workers' midgut, 1127 DEGs were identified in N. ceranae-infected workers' midgut at $7 \mathrm{dpi}$, including 327 up-regulated and 800 downregulated genes (Figure 2A), whereas 951 DEGs were identified in midgut at $10 \mathrm{dpi}$ with $N$. ceranae, including 275 up-regulated and 676 down-regulated genes (Figure 2B). In addition, 30 up-regulated and 94 down-regulated genes were shared by AcCK1 vs. AcT1 and AcCK2 vs. AcT2 comparison groups, whereas the numbers of specific upregulated (down-regulated) genes were 297 (706) and 245 (582) (Figure 2C,D). The shared up-regulated and down-regulated genes are shown in Table S2, while the specific upregulated and down-regulated genes are presented in Tables S3 and S4. 


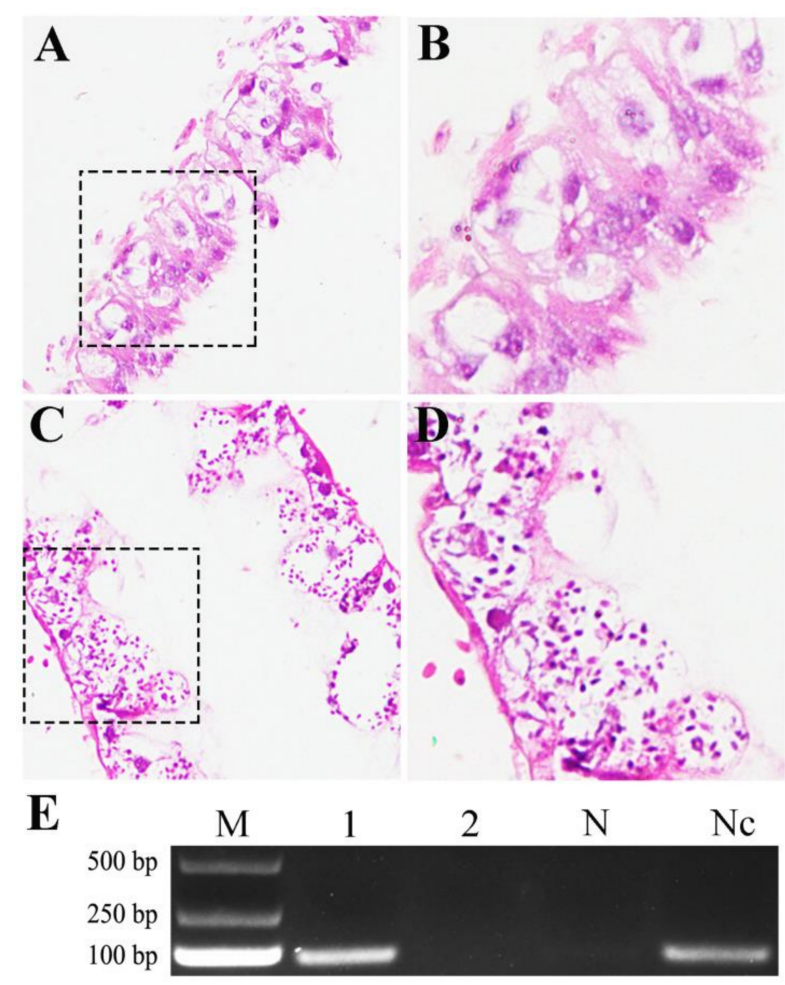

Figure 1. Confirmation of effective infection of A.c. cerana worker by N. ceranae. (A,B) Microscopic observation of paraffin section of workers' midgut at 12 dpi without $N$. ceranae under 200 times (A) and 400 times (B) amplification. (C,D) Microscopic observation of paraffin section of workers' midgut at $12 \mathrm{dpi}$ with $N$. ceranae under 200 times (C) and 400 times (D) amplification. Black dashed boxes show the selected regions for microscopic observation under 400 times amplification. (E) AGE for PCR amplification products from $N$. ceranae-inoculated workers' midgut and un-inoculated workers' midgut. Lane M: DNA marker; Lane 1: A. c. cerana workers' midgut at 12 dpi with N. ceranae; Lane 2: A. c. cerana workers' midgut at 12 dpi without N. ceranae; Lane N: sterile water (negative control); Lane Nc: clean spores of N. ceranae (positive control).
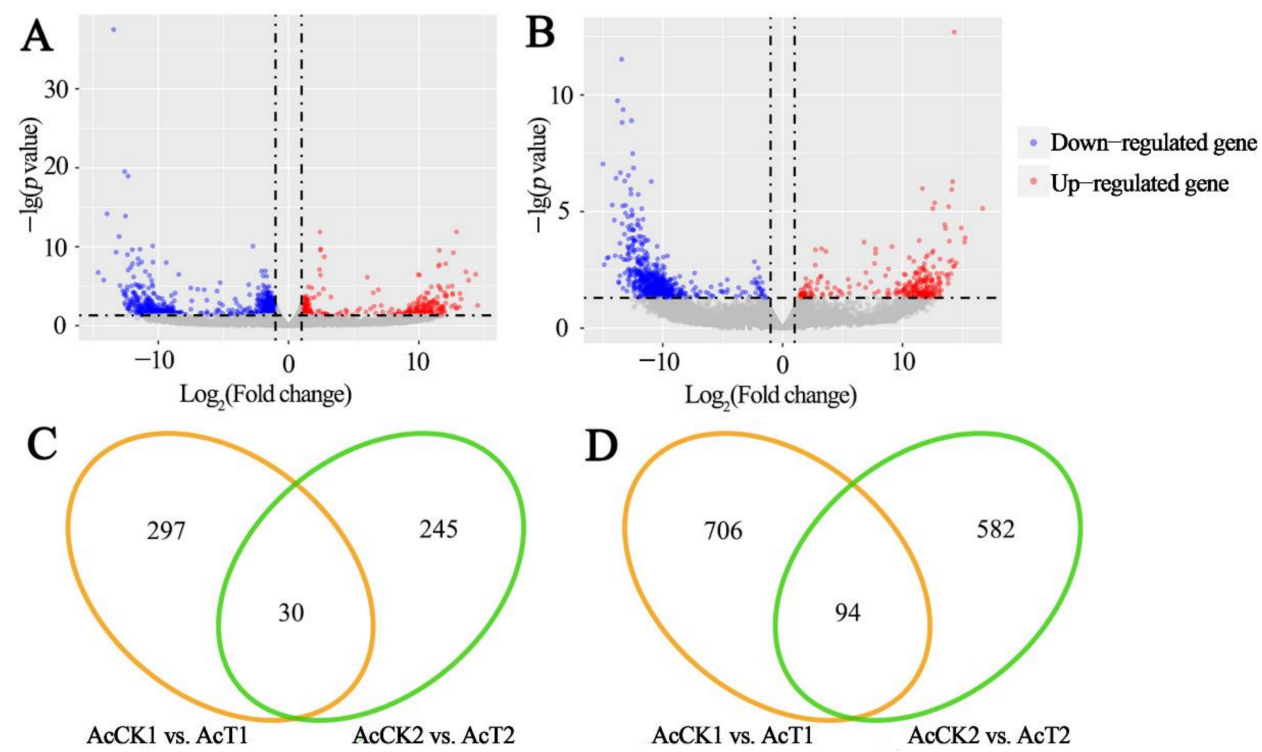

Figure 2. DEGs in A. c. cerana workers' midgut response to N. ceranae infection. (A,B) Valcano plots of DEGs within AcCK1 vs. AcT1 and AcCK2 vs. AcT2 comparison groups. (C,D) Venn analysis of up-regulated and down-regulated genes within two comparison groups. 
Furthermore, RT-qPCR results suggested that the differential expression trends of eight DEGs in AcCK1 vs. AcT1 and eight DEGs in AcCK2 vs. AcT2 were consistent with those in deep sequencing data (Figure 3), which validated the reliability of our transcriptome data.

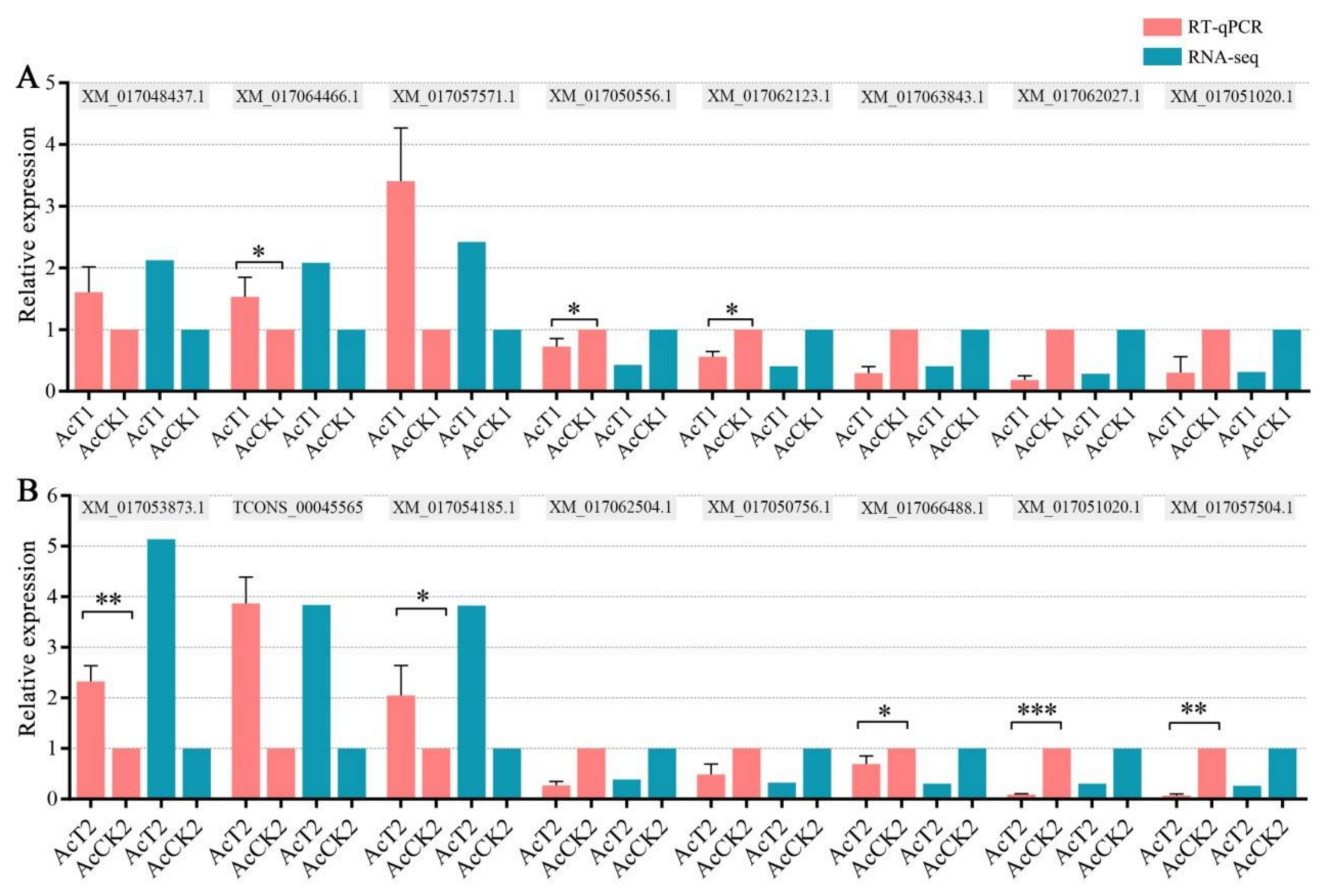

Figure 3. RT-qPCR validation of DEGs in AcCK1 vs. AcT1 (A) and AcCK2 vs. AcT2 (B) comparison group. ${ }^{*} p<0.05 ;{ }^{* *} p<0.01,{ }^{* * *} p<0.001$.

\subsection{GO Terms and KEGG Pathways Enriched by Host DEGs}

GO categorization demonstrated that DEGs in the AcCK1 vs. AcT1 comparison group were engaged in 13 biological process-associated functional terms such as cellular processes and single-organism processes, 11 cellular component-associated terms such as membrane parts and cell parts, and 10 molecular function-associated terms such as binding and catalytic activity (Figure 4A); whereas DEGs in the AcCK2 vs. AcT2 comparison group were involved in 33 functional terms relative to biological processes, cellular components, and molecular functions including cellular processes, single-organism processes, biological regulation, binding, and catalytic activity (Figure 4B).

Moreover, KEGG pathway enrichment analysis showed that DEGs in N. ceranaeinfected midgut at $7 \mathrm{dpi}$ could be enriched in 231 pathways. Among them, the most abundant ones were biosynthesis of secondary metabolites, protein processing in endoplasmic reticulum, RNA transport, insulin signaling pathway, and AMPK signaling pathway (Figure 5A), whereas DEGs in midgut at $10 \mathrm{dpi}$ with $N$. ceranae could be enriched in 226 pathways, the largest groups of which were biosynthesis of secondary metabolites, protein processing in endoplasmic reticulum, ubiquitin-mediated proteolysis, phosphatidylinositol signaling system, and glucagon signaling pathway (Figure 5B). 


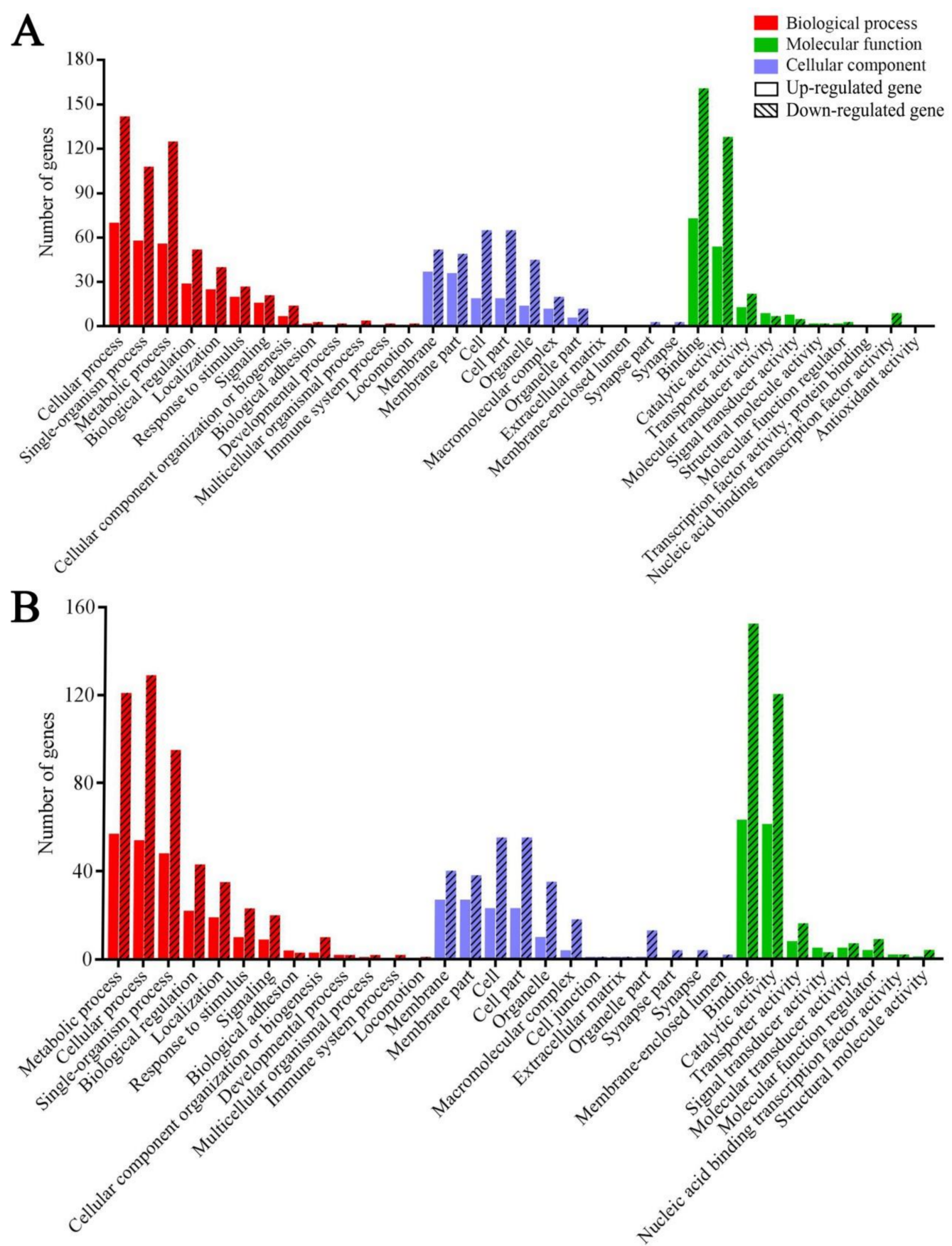

Figure 4. GO classification of DEGs in A. c. cerana workers' midguts at $7 \mathrm{dpi}(\mathbf{A})$ and $10 \mathrm{dpi}(\mathbf{B})$ with $N$. ceranae. 

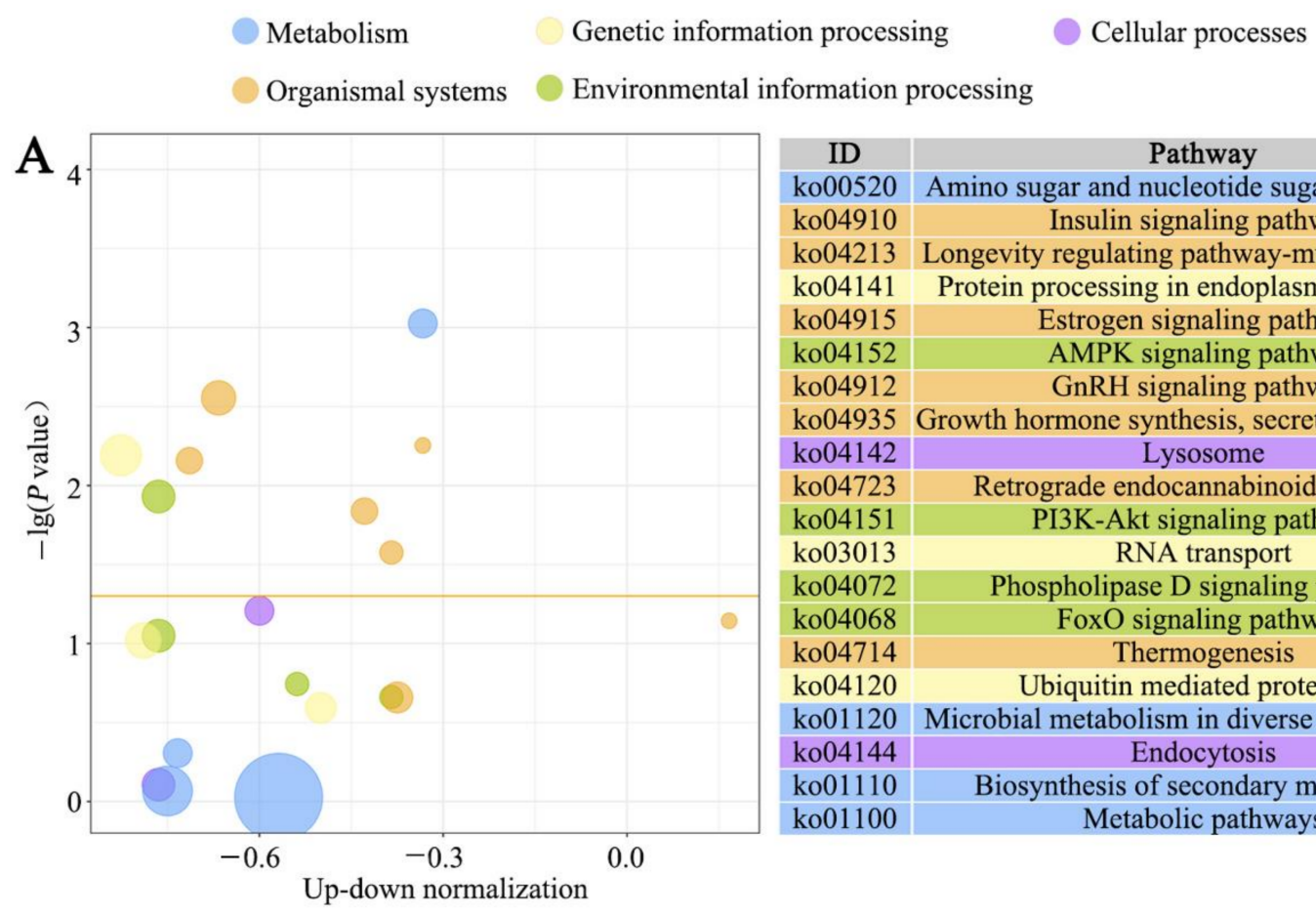

\begin{tabular}{|c|c|}
\hline ID & Pathway \\
\hline ko00520 & Amino sugar and nucleotide sugar metabolism \\
ko04910 & Insulin signaling pathway \\
ko04213 & Longevity regulating pathway-multiple species \\
ko04141 & Protein processing in endoplasmic reticulum \\
\hline ko04915 & Estrogen signaling pathway \\
ko04152 & AMPK signaling pathway \\
\hline ko04912 & GnRH signaling pathway \\
\hline ko04935 & Growth hormone synthesis, secretion and action \\
\hline ko04142 & Lysosome \\
\hline ko04723 & Retrograde endocannabinoid signaling \\
\hline ko04151 & PI3K-Akt signaling pathway \\
\hline ko03013 & RNA transport \\
\hline ko04072 & Phospholipase D signaling pathway \\
\hline ko04068 & FoxO signaling pathway \\
\hline ko04714 & Thermogenesis \\
\hline ko04120 & Ubiquitin mediated proteolysis \\
\hline ko01120 & Microbial metabolism in diverse environments \\
\hline ko04144 & Endocytosis \\
\hline ko01110 & Biosynthesis of secondary metabolites \\
\hline ko01100 & Metabolic pathways \\
\hline & \\
\hline
\end{tabular}

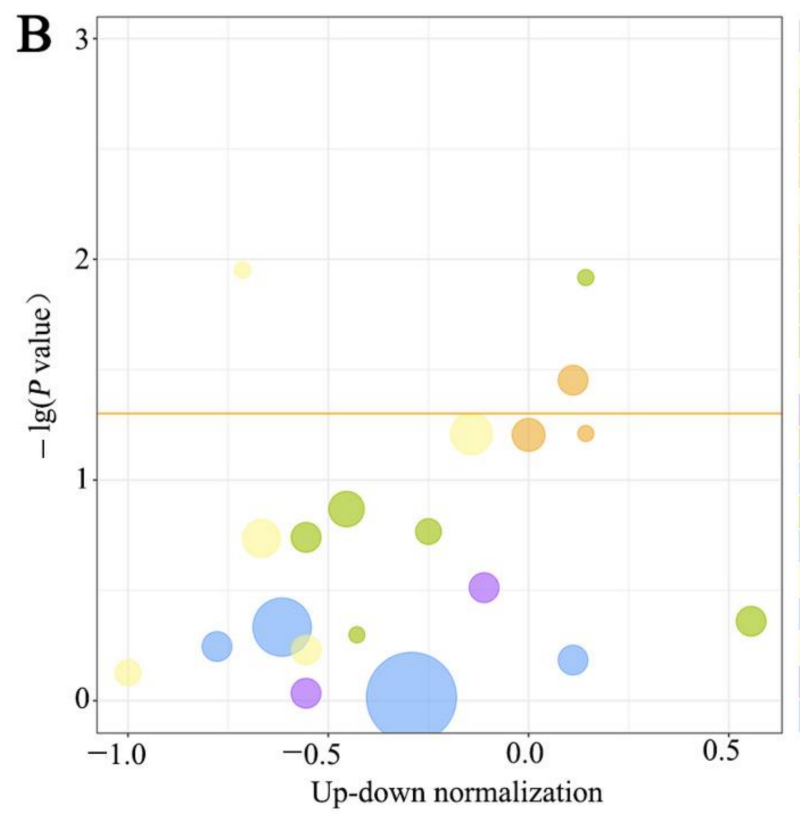

\begin{tabular}{|c|c|}
\hline ID & Pathway \\
\hline ko03030 & DNA replication \\
ko04330 & Notch signaling pathway \\
ko04722 & Neurotrophin signaling pathway \\
\hline ko04213 & Longevity regulating pathway - multiple species \\
\hline ko04141 & Protein processing in endoplasmic reticulum \\
ko04922 & Glucagon signaling pathway \\
\hline ko04070 & Phosphatidylinositol signaling system \\
\hline ko04013 & MAPK signaling pathway - fly \\
\hline ko04080 & Neuroactive ligand-receptor interaction \\
\hline ko04120 & Ubiquitin mediated proteolysis \\
\hline ko04140 & Autophagy - animal \\
\hline ko04310 & Wnt signaling pathway \\
\hline ko01110 & Biosynthesis of secondary metabolites \\
\hline ko04024 & cAMP signaling pathway \\
\hline ko00230 & Purine metabolism \\
\hline ko03013 & RNA transport \\
\hline ko01120 & Microbial metabolism in diverse environments \\
\hline ko03040 & Spliceosome \\
\hline ko04144 & Endocytosis \\
\hline ko01100 & Metabolic pathways \\
\hline
\end{tabular}

Figure 5. KEGG pathways enriched by DEGs in A. c. cerana workers' midguts at 7 dpi (A) and 10 dpi (B) with N. ceranae.

\subsection{Host DEGs Relevant to Cellular and Humoral Immune Pathways}

Based on the pathway analysis results, DEGs in N. ceranae-infected midgut at $7 \mathrm{dpi}$ were found to be involved in six cellular immune pathways (ubiquitin-mediated proteolysis, endocytosis, lysosome, phagosome, autophagy, and melanogenesis) and three humoral immune pathways (MAPK, Jak-STAT, and Toll/Imd signaling pathways) (Figure 6, see also Table S5). Similarly, DEGs in midgut at $10 \mathrm{dpi}$ with N. ceranae were also engaged in the aforementioned six cellular immune pathways and four humoral immune pathways (Figure 7, see also Table S6); additionally, one up-regulated gene (XM_017055397.1) was enriched in NF- $\kappa$ B signaling pathway (Figure 7, see also Table S6). 


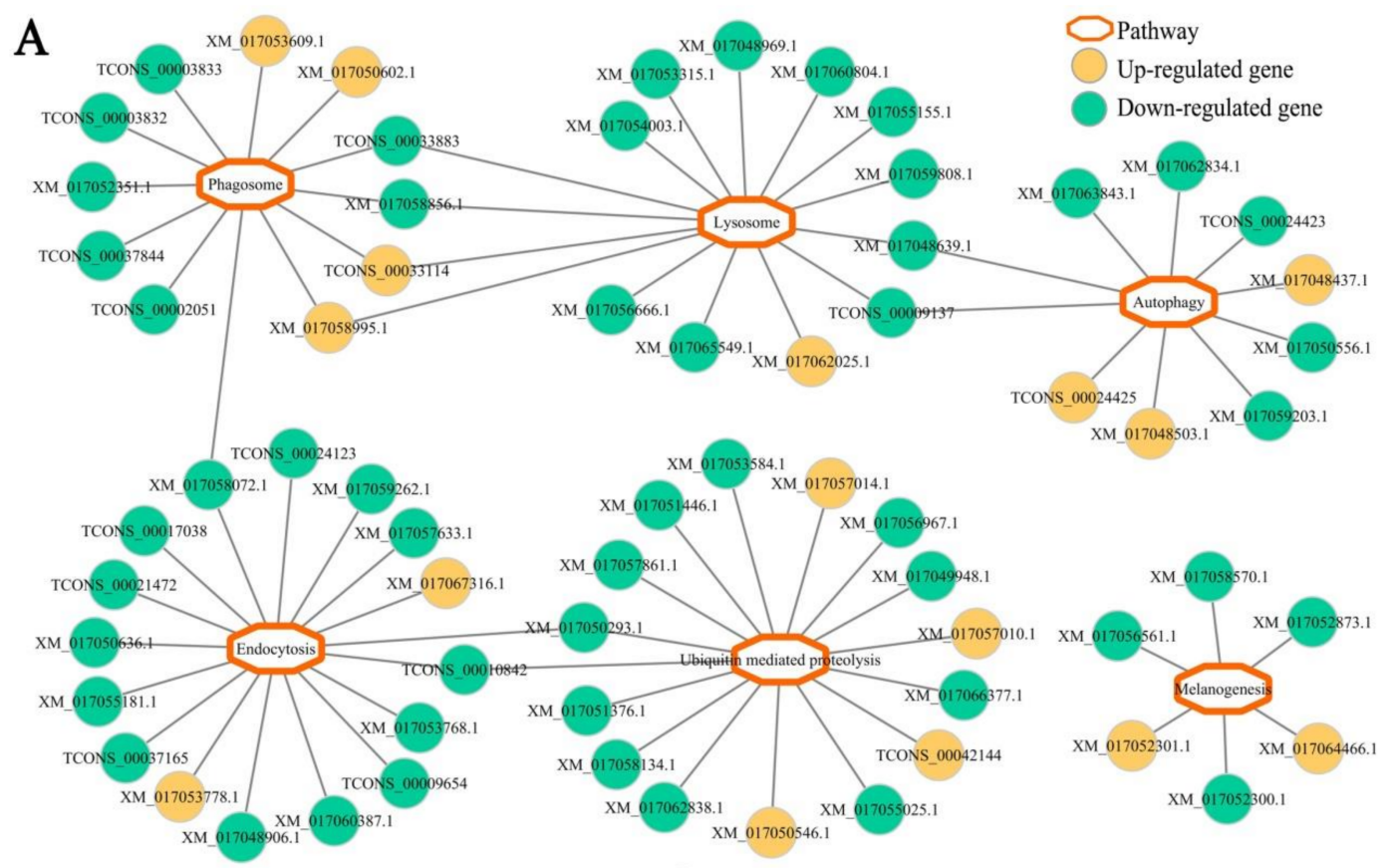

B

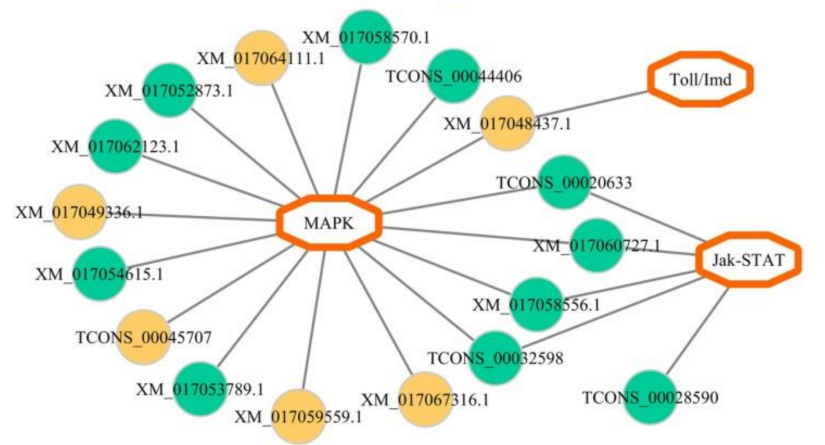

Figure 6. Enrichment network of host DEGs associated with cellular (A) and humoral (B) immune pathways in AcCK1 vs. AcT1 comparison group.

Further investigation of the regulatory network of cellular and humoral immune pathway-associated DEGs revealed that a majority of DEGs in both AcCK1 vs. AcT1 and $\mathrm{AcCK} 2$ vs. AcT2 comparison groups were engaged in only one immune pathway (Figures 6 and 7), whereas a small quantity of DEGs were simultaneously involved in two immune pathways. For example, XM_017048639.1 with up-regulated expression in workers' midgut at 7 dpi was simultaneously enriched in autophagy and lysosome, and TCONS_00032598 was up-regulated in workers' midgut at $10 \mathrm{dpi}$ and simultaneously enriched in MAPK and Jak-STAT signaling pathways (Figures 6 and 7). Detailed information about cellular and humoral immune pathway-related DEGs in N. ceranae-infected A. c. cerana workers' midguts at $7 \mathrm{dpi}$ and $10 \mathrm{dpi}$ is summarized in Tables S7 and S8, respectively. 


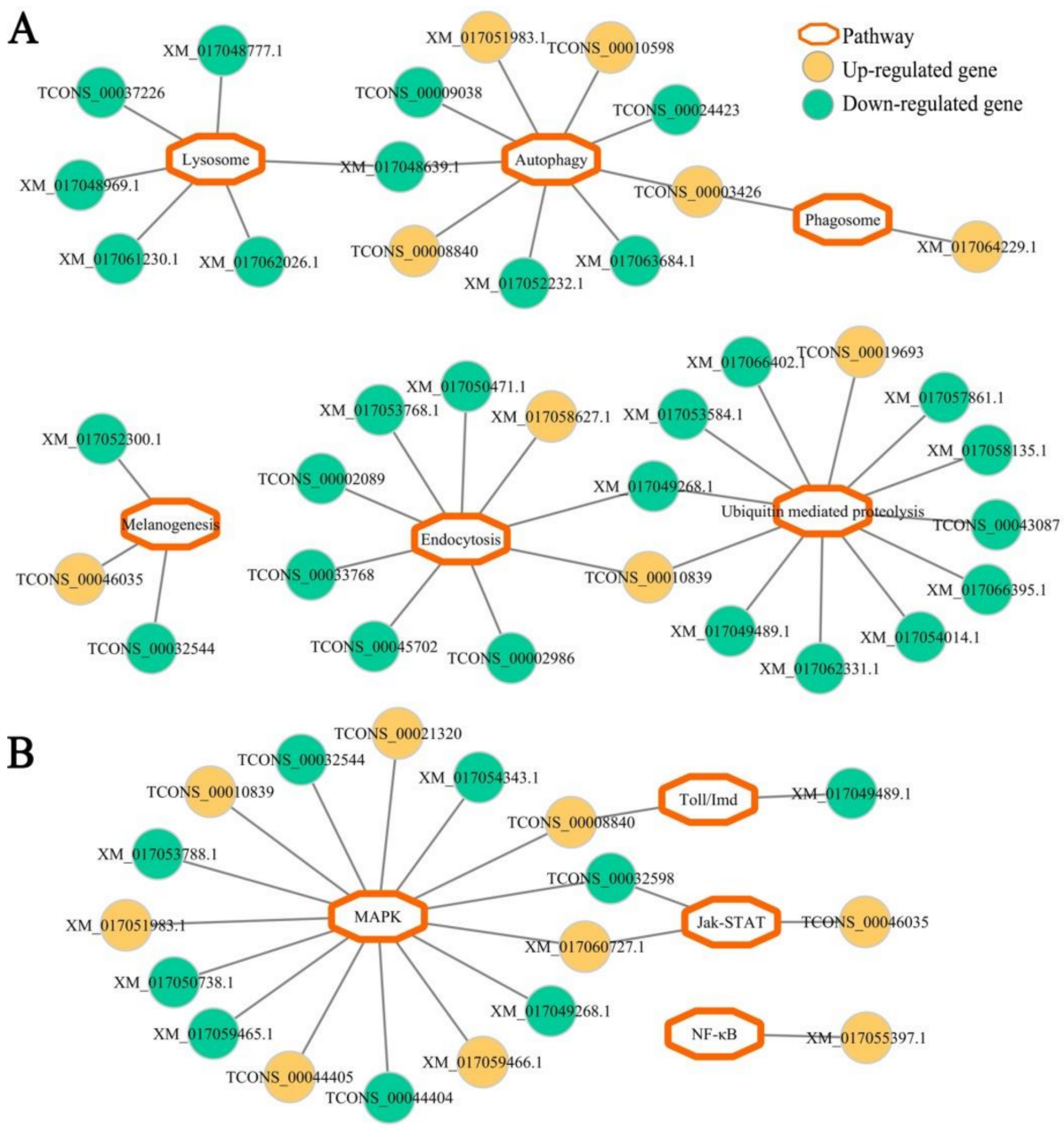

Figure 7. Enrichment network of host DEGs relevant to cellular (A) and humoral (B) immune pathways in AcCK2 vs. AcT2 comparison group.

\section{Discussion}

In our previous work, $A . m$. ligustica workers' midguts at $7 \mathrm{dpi}$ and $10 \mathrm{dpi}$ with $N$. ceranae were selected for next-generation sequencing based on three major points: (1) the life cycle of $N$. ceranae is approximately $6 \mathrm{~d}$ [55]; (2) the number of fungal spores in the infected midgut of $A$. m. ligustica worker continuously increased during a 1-20 d period [56]; (3) the cumulative mortality rate of $N$. ceranae-infected workers was significantly higher than that of uninfected workers at $7 \mathrm{dpi}$ and $10 \mathrm{dpi}$ [52]. We previously performed strandspecific cDNA library-based deep sequencing of un-inoculated midguts and N. ceranaeinoculated A. c. cerana workers' midguts at $7 \mathrm{dpi}$ and $10 \mathrm{dpi}$ following the findings from previous studies on $A$. mellifera- $N$. ceranae interaction [29,46,55-57]. Here, we first investigated immune response of $A$. c. cerana workers' midguts to $N$. ceranae infection at a transcriptomic level, and 1127 and 951 DEGs were respectively identified in N. ceranaeinfected workers' midguts at $7 \mathrm{dpi}$ and $10 \mathrm{dpi}$ when compared with uninfected workers' midguts, indicating that overall alteration of host gene expression profile was caused by fungal invasion. Another reason for sequencing midgut samples at the above-mentioned two time points was to better compare N. ceranae-response between A. c. cerana workers and $A$. m. ligustica workers. Honeybee midgut is a vital site for food digestion, nutrient absorption, detoxification, and immunity, but also the main site for $N$. ceranae proliferation and host-microspodian interaction [58]. As for western honeybee-N. ceranae interaction, midgut tissue was usually selected for investigation in previous studies $[15,21,58,59]$. Therefore, transcriptome data from midguts of A. c. cerana workers challenged by N. ceranae were believed to more accurately reflect host immune response. 
As a eusocial insect, honeybees have evolved both colony-level and individual-level strategies to defense against various pathogens and parasites [60]. Here, we focused on the individual-level immune response of the A. c. cerana worker to N. ceranae infection. Similarly to vertebrates, insects defend themselves against an array of microbes and parasites by invoking various innate immune responses [61]. In honeybees, cuticle and peritrophic membrane are the physical barriers to combat fungal pathogens. When the first line of defense is pierced, host cellular and humoral immune systems are activated to fight against the invading fungi [62-64]. Autophagy literally translates as "eating of self", which is not only an evolutionarily conserved stress-responsive cytosolic process in both vertebrates and invertebrates, but also an intracellular multistep process responsible for the degradation and recycling of cytoplasmic contents by lysosomal proteases $[65,66]$. However, little is known about autophagy in honeybee response to infections by various pathogens. Here, three and four up-regulated genes were found to be enriched in autophagy in A. c. cerana workers' midguts at $7 \mathrm{dpi}$ and $10 \mathrm{dpi}$ with $N$. ceranae. Autophagy is relevant to the resistance of mammalian cells to bacteria, viruses, and parasites [67-69]. In insects such as Drosophila melanogaster and Aedes aegypti, autophagy has been proved to be associated with host resistance to bacterial and viral challenges $[70,71]$. The results indicated that the autophagy pathway may be activated and employed by the host to combat N. ceranae. Additionally, in workers' midgut at $10 \mathrm{dpi}$, one up-regulated gene encoding phosphatidylinositol 3-kinase catalytic subunit type 3-like isoform X2 [TCONS_00003426, $\log _{2}($ fold change $)=12.17$ ] was simultaneously enriched in autophagy and lysosome (Figure 7A), suggestive of the importance of TCONS_00003426 in cellular immune response of the host to N. ceranae infection. Moreover, seven and five genes with down-regulation were respectively enriched in autophagy in N. ceranae-infected workers' midguts at $7 \mathrm{dpi}$ and $10 \mathrm{dpi}$. Although autophagy has been regarded as a cornerstone of host defense and intracellular surveillance, it has been suggested that intracellular bacteria and viruses modify autophagy to enhance their infections [72,73]. This was suggestive of the inhibition of the autophagy pathway in A. c. cerana workers' midgut by N. ceranae. Interestingly, in workers' midgut at $7 \mathrm{dpi}$, two down-regulated genes encoding lysosomal aspartic protease-like (TCONS_00009137, $\log _{2}($ fold change $\left.)=-11.16\right)$ and lysosomal aspartic protease (XM_017048639.1, $\log _{2}$ (fold change) $=-1.17$ ) were simultaneously enriched in autophagy and lysosome (Figure 6A), implying that TCONS_00009137 and XM_017048639.1, as two key players in host cellular immune response, were likely to be manipulated by N. ceranae.

Here, eight down-regulated genes were involved in phagosome in workers' midgut at $7 \mathrm{dpi}$, whereas up-regulation of two phagosome-associated genes was observed in workers' midgut at $10 \mathrm{dpi}$ (Figures $6 \mathrm{~A}$ and $7 \mathrm{~A}$ ). Phagocytosis is a fundamental innate immune mechanism used by mammals and insects [61]. In honeybees, phagocytosis is one of the most common defense mechanisms to cope with fungal pathogens [62]. The results indicated that the phagosome pathway in host midgut was first inhibited and then markedly activated during N. ceranae infection. Comparatively, in the midguts of A. $m$. ligustica workers at $7 \mathrm{dpi}$ and $10 \mathrm{dpi}$ with $N$. ceranae, there was no DEG enriched in phagosome [30]. Together, these findings suggested that the phagosome pathway and corresponding DEGs may play a special role in cellular immune response of A.c. cerana workers to N. ceranae invasion. Of note, four up-regulated genes were involved in ubiquitinmediated proteolysis in workers' midgut at $7 \mathrm{dpi}$, while more genes (12) enriched in this cellular immune pathway were down-regulated (Figure 6A). A similar situation was detected in the midguts of $A$.c. cerana workers at $10 \mathrm{dpi}$. As a key mechanism for clearing unneeded or damaged cells, the ubiquitin proteasome degradation system plays a pivotal part in regulating most cellular processes including the cell cycle and immunity [74]. This result demonstrated that ubiquitin-mediated proteolysis in host midgut was suppressed to a large extent by N. ceranae. In A. m. ligustica workers' midguts at $7 \mathrm{dpi}$ and $10 \mathrm{dpi}$ with $N$. ceranae, two and two genes involved in ubiquitin-mediated proteolysis were previously found to be up-regulated, respectively, indicative of the activation of this cellular immune pathway during N. ceranae infection [30]. As a highly host-dependent 
fungal parasite, $N$. ceranae is able to induce multidimensional physiological alterations in bee hosts including energetic stress, decreased homing ability, and earlier foraging activity [75-77]. Additionally, immune suppression caused by N. ceranae infection was observed in western honeybees $[15,22,23]$. Therefore, these results revealed that cellular immune pathways in A. c. cerana workers' midguts were suppressed by N. ceranae to some extent via host-microsporidian interaction.

In this current work, Venn analysis displayed that the numbers of specific up-regulated genes were 297 and 245, which were much less than those (706 and 582) of specific downregulated genes in AcCK1 vs. AcT1 and AcCK2 vs. AcT2; additionally, only 124 DEGs were shared by the above-mentioned two comparison groups, including 30 up-regulated and 94 down-regulated genes. It is speculated that some DEGs in A.c. cerana workers' midguts continuously exerted key functions during $N$. ceranae invasion, whereas more unique DEGs were involved in host response to fungal infection at various stages. Further, we note that a total of six common genes were enriched in the ubiquitin-mediated proteolysis pathway, and all presented a down-regulated trend in workers' midguts at both $7 \mathrm{dpi}$ and 10 dpi (Table S2). In addition, an apoptosis-inducing factor 1 encoding gene was obviously down-regulated in workers' midguts at $7 \mathrm{dpi}\left(\log _{2}\right.$ (fold change $\left.)=-10.81\right)$ and $10 \mathrm{dpi}$ $\left(\log _{2}(\right.$ fold change $\left.)=-12.19\right)$. These results suggested that the aforementioned two cellular immune pathways were suppressed by N. ceranae at different stages of fungal infection.

One up-regulated gene was previously discovered to be enriched in apoptosis in the midguts of $A$. m. ligustica workers at $7 \mathrm{dpi}$ and $10 \mathrm{dpi}$ with $N$. ceranae, respectively, suggesting that that apoptosis pathway was activated to combat $N$. ceranae infection [30]. Intriguingly, there was no DEG enriched in apoptosis in this work. Apoptosis plays a primary role in the growth and development of vertebrates and invertebrates [78]. This strategy is also employed by insects to fight against pathogens $[79,80]$. In western honeybees, N. ceranae was shown to suppress apoptosis in host midgut epithelial cells $[15,19,28]$. However, N. ceranae-tolerant A. mellifera workers could escape parasitic manipulation of apoptosis [20]. That finding demonstrated that this cellular immune pathway was not engaged in A.c. cerana worker midguts responding to N. ceranae invasion.

After fungal infection, insect humoral immunity is induced to synthesize AMPs and activate the prophenoloxodase system, which can work together to inactivate or kill the invaders [81]. Currently, most of the knowledge regarding insect humoral immunity is derived from studies associated with on model insects such as Drosophila and mosquito. The NF- $\kappa$ B pathway, a conserved signal transduction pathway present in nearly all mammalian cell types, is involved in various biological processes including innate and adaptive immunity, survival, development, proliferation, and cell apoptosis [82,83]. Here, one upregulated gene was involved in the NF- $\kappa \mathrm{B}$ pathway in $N$. ceranae-challenged A. c. cerana workers' midgut at $10 \mathrm{dpi}$, and one up-regulated gene and one down-regulated gene were enriched in the Toll-like receptor signaling pathway (Figure 7B), whereas in workers' midgut at $7 \mathrm{dpi}$, one gene enriched in the Toll-like receptor signaling pathway was found to be up-regulated (Figure 6B). Drosophila possess two NF- $\kappa$ B signaling pathways (Toll and Imd) that are uniquely active against different pathogens [84-87]. The Toll pathway is activated mainly by fungal and Gram-positive bacterial infections and controls in large part the expression of AMPs active against fungal pathogens, whereas the Imd pathway responds mainly to Gram-negative bacteria infections and controls the gene expression of antibacterial peptides [87-89]. In the midguts of A. m. ligustica workers at both $7 \mathrm{dpi}$ and $10 \mathrm{dpi}$ with $N$. ceranae, one up-regulated gene was enriched in the NF- $\kappa \mathrm{B}$ pathway, implying that this humoral immune pathway was activated by $N$. ceranae infection [30]. These results indicated that the NF- $\kappa$ B pathway may play a pivotal role in immune responses of both eastern honeybee workers and western honeybee workers to N. ceranae invasion. In addition, five genes enriched in the Jak-STAT pathway were up-regulated in workers' midgut at $7 \mathrm{dpi}$, while three DEGs in workers' midgut at $10 \mathrm{dpi}$ were engaged in this humoral immune pathway, including two up-regulated genes (Figures $6 \mathrm{~B}$ and 7B). The Jak-STAT pathway was verified to be required for the antiviral response in Drosophila [90,91]. 
Jak-STAT-deficient flies are resistant to fungal and bacterial infections but susceptible to viral infections [92]. This immune pathway was also well-activated in Anopheles gambiae responding to bacterial infection [91]. Additionally, similarly to the Toll pathway, the Jak-STAT pathway regulates several other developmental and physiological functions in insects [93]. It has been demonstrated that the Jak-STAT pathway in A. c. cerana workers' midguts was activated due to $N$. ceranae infection. Intriguingly, there was no DEG enriched in the Jak-STAT pathway in A. m. ligustica workers' midguts in response to N. ceranae infection [30]. Together, these results demonstrated that different humoral immune responses were employed by A.c. cerana workers and A. m. ligustica workers to battle the same fungal parasite, N. ceranae.

Additional work is needed to decipher the function of key immune genes with differential expression in A. c. cerana worker response to N. ceranae invasion. That effort can be expected to provide knowledge for the development of effective and environmentally friendly strategies to control bee nosemosis.

\section{Conclusions}

In the present study, cellular and humoral immune responses of A.c. ceranae workers' midguts to $N$. ceranae invasion were comprehensively investigated at a transcriptome-wide level. These results demonstrated that the overall gene expression profile in host midgut was altered by $N$. ceranae invasion and that some host immune pathways such as the autophagy and Jak-STAT pathway were induced to activation during fungal infection, whereas some were suppressed via host-pathogen interaction. Our findings not only offer a basis for clarification of the mechanism underlying the immune response of $A$.c. cerana to $N$. ceranae infection, but also provide novel insights into eastern honeybee-microsporidian interaction.

Supplementary Materials: The following are available online at https:/ / www.mdpi.com/article/10 .3390 /insects12080728/s1. Figure S1. Agarose gel electrophoresis for PCR amplification products from the midgut of newly emerged A. c. cerana worker, Table S1. Primers for RT-PCR and RT-qPCR in this research, Table S2. Information about the shared DEGs between AcCK1 vs. AcT1 and AcCK2 vs. AcT2 comparison groups, Table S3. Information about the specific DEGs in AcCK1 vs. AcT1 comparison group, Table S4. Information about the specific DEGs in AcCK2 vs. AcT2 comparison group, Table S5. Summary of cellular and humoral immune pathways enriched by DEGs in AcCK1 vs. AcT1 comparison group, Table S6. Summary of cellular and humoral immune pathways enriched by DEGs in AcCK2 vs. AcT2 comparison group, Table S7. Detailed information about cellular and humoral immune pathway-associated host DEGs at 7 dpi with N. ceranae, Table S8. Detailed information about cellular and humoral immune pathway-associated host DEGs at 10 dpi with N. ceranae.

Author Contributions: Conceptualization, R.G.; methodology, W.X. and D.Z.; software, W.X., D.Z., Q.L. and M.S.; validation, W.X., D.Z., Q.L. and M.S.; formal analysis, W.X., D.Z., Q.L., M.S. and L.W.; investigation, W.X., D.Z., Q.L., M.S. and L.W.; resources, R.G.; data curation, R.G., W.X., D.Z. and L.W.; writing—original draft preparation, R.G., W.X., D.Z., Q.L., M.S. and L.W.; writing-review and editing, R.G., W.X., D.Z., Q.L., M.S. and L.W.; visualization, W.X., D.Z., Q.L., M.S. and L.W.; supervision, R.G.; project administration, R.G.; funding acquisition, R.G. All authors have read and agreed to the published version of the manuscript.

Funding: This study was financially supported by the Outstanding Scientific Research Manpower Fund of Fujian Agriculture and Forestry University (xjq201814), the Scientific and Technical Innovation Fund of Fujian Agriculture and Forestry University (CXZX2017342).

Acknowledgments: We thank all editors and reviewers for their constructive comments and recommendations.

Conflicts of Interest: The authors declare that they have no conflict of interest. 


\section{References}

1. Calderone, N.W. Insect pollinated crops, insect pollinators and US agriculture: Trend analysis of aggregate data for the period 1992-2009. PLoS ONE 2012, 7, e37235. [CrossRef]

2. Wang, M.; Xiao, Y.; Li, Y.; Wang, X.; Qi, S.; Wang, Y.; Zhao, L.; Wang, K.; Peng, W.; Luo, G.Z.; et al. RNA m ${ }^{6}$ A modification functions in larval development and caste differentiation in honeybee (Apis mellifera). Cell Rep. 2021, 34, 108580. [CrossRef]

3. Zayed, A.; Robinson, G.E. Understanding the relationship between brain gene expression and social behavior: Lessons from the honey bee. Annu. Rev. Genet. 2012, 46, 591-615. [CrossRef]

4. Lee, K.V.; Steinhauer, N.; Rennich, K.; Wilson, M.E.; Tarpy, D.R.; Caron, D.M. A national survey of managed honey bee 2013-2014 annual colony losses in the USA. Apidologie 2015, 46, 292-305. [CrossRef]

5. Foret, S.; Kucharski, R.; Pellegrini, M.; Feng, S.; Jacobsen, S.E.; Robinson, G.E.; Maleszka, R. DNA methylation dynamics, metabolic fluxes, gene splicing, and alternative phenotypes in honey bees. Proc. Natl. Acad. Sci. USA 2012, 109, $4968-4973$. [CrossRef]

6. $\quad$ Li-Byarlay, H.; Li, Y.; Stroud, H.; Feng, S.; Newman, T.C.; Kaneda, M.; Hou, K.K.; Worley, K.C.; Elsik, C.G.; Wickline, S.A.; et al. RNA interference knockdown of DNA methyltransferase 3 affects gene alternative splicing in the honey bee. Proc. Natl. Acad. Sci. USA 2013, 110, 12750-12755. [CrossRef] [PubMed]

7. Schulte, C.; Theilenberg, E.; Müller-Borg, M.; Gempe, T.; Beye, M. Highly efficient integration and expression of piggyBac-derived cassettes in the honeybee (Apis mellifera). Proc. Natl. Acad. Sci. USA 2014, 111, 9003-9008. [CrossRef] [PubMed]

8. Hu, X.F.; Zhang, B.; Liao, C.H.; Zeng, Z.J. High-efficiency CRISPR/Cas9-mediated gene editing in honeybee (Apis mellifera) embryos. G3 Genes Genom. Genet. 2019, 9, 1759-1766. [CrossRef]

9. Higes, M.; García-Palencia, P.; Urbieta, A.; Nanetti, A.; Martín-Hernández, R. Nosema apis and Nosema ceranae tissue tropism in worker honey bees (Apis mellifera). Vet. Pathol. 2020, 57, 132-138. [CrossRef] [PubMed]

10. Martín-Hernández, R.; Bartolomé, C.; Chejanovsky, N.; Le Conte, Y.; Dalmon, A.; Dussaubat, C.; García-Palencia, P.; Meana, A.; Pinto, M.A.; Soroker, V.; et al. Nosema ceranae in Apis mellifera: A 12 years postdetection perspective. Environ. Microbiol. 2018, 20, 1302-1329. [CrossRef] [PubMed]

11. Fries, I.; Feng, F.; da Silva, A.; Slemenda, S.B.; Pieniazek, N.J. Nosema ceranae n. sp. (Microspora, Nosematidae), morphological and molecular characterization of a microsporidian parasite of the Asian honey bee Apis cerana (Hymenoptera, Apidae). Eur. J. Protistol. 1996, 32, 356-365. [CrossRef]

12. Klee, J.; Besana, A.M.; Genersch, E.; Gisder, S.; Nanetti, A.; Tam, D.Q.; Chinh, T.X.; Puerta, F.; Ruz, J.M.; Kryger, P.; et al. Widespread dispersal of the microsporidian Nosema ceranae, an emergent pathogen of the western honey bee, Apis mellifera. J. Invertebr. Pathol. 2007, 96, 1-10. [CrossRef]

13. Gisder, S.; Schüler, V.; Horchler, L.L.; Groth, D.; Genersch, E. Long-term temporal trends of Nosema spp. infection prevalence in Northeast Germany: Continuous spread of Nosema ceranae, an emerging pathogen of honey bees (Apis mellifera), but no general replacement of Nosema apis. Front. Cell. Infect Microbiol. 2017, 7, 301. [CrossRef]

14. Paris, L.; El Alaoui, H.; Delbac, F.; Diogon, M. Effects of the gut parasite Nosema ceranae on honey bee physiology and behavior. Curr. Opin. Insect Sci. 2018, 26, 149-154. [CrossRef]

15. Holt, H.L.; Aronstein, K.A.; Grozinger, C.M. Chronic parasitization by Nosema microsporidia causes global expression changes in core nutritional, metabolic and behavioral pathways in honey bee workers (Apis mellifera). BMC Genom. 2013, 14, 799. [CrossRef]

16. Dussaubat, C.; Sagastume, S.; Gómez-Moracho, T.; Botías, C.; García-Palencia, P.; Martín-Hernández, R.; Le Conte, Y.; Higes, M. Comparative study of Nosema ceranae (Microsporidia) isolates from two different geographic origins. Vet. Microbiol. 2013, 162, 670-678. [CrossRef] [PubMed]

17. García-Palencia, P.; Martín-Hernández, R.; González-Porto, A.; Marin, P.; Meana, A.; Higes, M. Natural infection by Nosema ceranae causes similar lesions as in experimentally infected caged-workers honey bees (Apis mellifera). J. Apic. Res. 2010, 49, 278-283. [CrossRef]

18. Mayack, C.; Naug, D. Energetic stress in the honeybee Apis mellifera from Nosema ceranae infection. J. Invertebr. Pathol. 2009, 100, 185-188. [CrossRef] [PubMed]

19. Higes, M.; Juarranz, Á.; Dias-Almeida, J.; Lucena, S.; Botías, C.; Meana, A.; García-Palencia, P.; Martín-Hernández, R. Apoptosis in the pathogenesis of Nosema ceranae (Microsporidia: Nosematidae) in honey bees (Apis mellifera). Environ. Microbiol. Rep. 2013, 5, 530-536. [CrossRef] [PubMed]

20. Kurze, C.; Le Conte, Y.; Dussaubat, C.; Erler, S.; Kryger, P.; Lewkowski, O.; Müller, T.; Widder, M.; Moritz, R.F. Nosema tolerant honeybees (Apis mellifera) escape parasitic manipulation of apoptosis. PLoS ONE 2015, 10, e0140174. [CrossRef]

21. Kurze, C.; Le Conte, Y.; Kryger, P.; Lewkowski, O.; Müller, T.; Moritz, R. Infection dynamics of Nosema ceranae in honey bee midgut and host cell apoptosis. J. Invertebr. Pathol. 2018, 154, 1-4. [CrossRef] [PubMed]

22. Antúnez, K.; Martín-Hernández, R.; Prieto, L.; Meana, A.; Zunino, P.; Higes, M. Immune suppression in the honey bee (Apis mellifera) following infection by Nosema ceranae (Microsporidia). Environ. Microbiol. 2009, 11, 2284-2290. [CrossRef] [PubMed]

23. Chaimanee, V.; Chantawannakul, P.; Chen, Y.; Evans, J.D.; Pettis, J.S. Differential expression of immune genes of adult honey bee (Apis mellifera) after inoculated by Nosema ceranae. J. Insect. Physiol. 2012, 58, 1090-1095. [CrossRef]

24. Osta, M.A.; Christophides, G.K.; Vlachou, D.; Kafatos, F.C. Innate immunity in the malaria vector Anopheles gambiae: Comparative and functional genomics. J. Exp. Biol. 2004, 207, 2551-2563. [CrossRef] [PubMed] 
25. Casteels-Josson, K.; Zhang, W.; Capaci, T.; Casteels, P.; Tempst, P. Acute transcriptional response of the honeybee peptideantibiotics gene repertoire and required post-translational conversion of the precursor structures. J. Biol. Chem. 1994, 269, 28569-28575. [CrossRef]

26. Garrido, P.M.; Porrini, M.P.; Antúnez, K.; Branchiccela, B.; Martínez-Noël, G.M.; Zunino, P.; Salerno, G.; Eguaras, M.J.; Ieno, E. Sublethal effects of acaricides and Nosema ceranae infection on immune related gene expression in honeybees. Vet. Res. 2016, 47, 51. [CrossRef]

27. Sinpoo, C.; Paxton, R.J.; Disayathanoowat, T.; Krongdang, S.; Chantawannakul, P. Impact of Nosema ceranae and Nosema apis on individual worker bees of the two host species (Apis cerana and Apis mellifera) and regulation of host immune response. J. Insect Physiol. 2018, 105, 1-8. [CrossRef]

28. Aufauvre, J.; Misme-Aucouturier, B.; Vigues, B.; Texier, C.; Delbac, F.; Blot, N. Transcriptome analyses of the honeybee response to Nosema ceranae and insecticides. PLoS ONE 2014, 9, e91686. [CrossRef]

29. Dussaubat, C.; Brunet, J.L.; Higes, M.; Colbourne, J.K.; Lopez, J.; Choi, J.H.; MartinHernandez, R.; Botias, C.; Cousin, M.; McDonnell, C.; et al. Gut pathology and responses to the microsporidium Nosema ceranae in the honey bee Apis mellifera. PLoS ONE 2012, 7, e37017. [CrossRef]

30. Fu, Z.M.; Chen, H.Z.; Liu, S.Y.; Zhu, Z.W.; Fan, X.X.; Fan, Y.C.; Wan, J.Q.; Zhang, L.; Xiong, C.L.; Xu, G.J.; et al. Immune responses of Apis mellifera ligustica to Nosema ceranae stress. Sci. Agric. Sin. 2019, 52, 3069-3082.

31. Geng, S.H.; Zhou, D.D.; Fan, X.X.; Jiang, H.B.; Zhu, Z.W.; Wang, J.; Fan, Y.C.; Wang, X.R.; Xiong, C.L.; Zheng, Y.Z.; et al. Transcriptome analysis reveals the molecular mechanism underlying Nosema ceranae infection of Apis mellifera ligustica. Acta Entomol. Sin. 2020, 63, 294-308.

32. Radlof, S.E.; Hepburn, C.; Hepburn, H.R.; Fuchs, S.; Hadisoesilo, S.; Tan, K.; Engel, M.S.; Kuznetsov, V. Population structure and classifcation of Apis cerana. Apidologie 2010, 41, 589-601. [CrossRef]

33. Brown, M.J.F. Oldroyd Benjamin Siriwat Wongsiri Asian honey bees. Biology, Conservation, and Human Interactions. Harvard University Press Cambridge, Massachusetts Pp. Anim. Behav. 2006, 73, 553-554. [CrossRef]

34. Peng, Y.S.; Fang, Y.Z.; Xu, S.Y.; Ge, L.S. The resistance mechanism of the Asian honey bee, Apis cerana Fabr., to an ectoparasitic mite, Varroa jacobsoni Oudemans. J. Invertebr. Pathol. 1987, 49, 54-60. [CrossRef]

35. Xu, P.; Shi, M.; Chen, X.X. Antimicrobial peptide evolution in the Asiatic honey bee Apis cerana. PLoS ONE 2009,4 , e4239. [CrossRef]

36. Liu, L.; Qin, M.; Yang, L.; Song, Z.; Luo, L.; Bao, H.; Ma, Z.; Zhou, Z.; Xu, J. A genome-wide analysis of simple sequence repeats in Apis cerana and its development as polymorphism markers. Gene 2017, 599, 53-59. [CrossRef] [PubMed]

37. Ono, M.; Okada, I.; Sasaki, M. Heat protection by balling in the Japanese honeybee Apis cerana japonica as a defensive behavior against the hornet, Vespa simillima xanthoptera (Hymenoptera: Vespidae). Experientia 1987, 43, 1031-1034. [CrossRef]

38. Chen, D.; Du, Y.; Chen, H.; Fan, Y.; Fan, X.; Zhu, Z.; Wang, J.; Xiong, C.; Zheng, Y.; Hou, C.; et al. Comparative identification of micrornas in Apis cerana cerana workers' midguts in response to Nosema ceranae invasion. Insects 2019, 10, 258. [CrossRef]

39. Chen, Y.; Evans, J.D.; Smith, I.B.; Pettis, J.S. Nosema ceranae is a long-present and wide-spread microsporidian infection of the European honey bee (Apis mellifera) in the United States. J. Invertebr. Pathol. 2008, 97, 186-188. [CrossRef]

40. Benjeddou, M.; Leat, N.; Allsopp, M.; Davison, S. Detection of acute bee paralysis virus and black queen cell virus from honeybees by reverse transcriptase pcr. Appl. Environ. Microbiol. 2001, 67, 2384-2387. [CrossRef]

41. Genersch, E. Development of a rapid and sensitive RT-PCR method for the detection of deformed wing virus, a pathogen of the honeybee (Apis mellifera). Vet. J. 2005, 169, 121-123. [CrossRef] [PubMed]

42. Ribiere, M.; Triboulot, C.; Mathieu, L.; Aurieres, C.; Faucon, J.P.; Pepin, M. Molecular diagnosis of chronic bee paralysis virus infection. Apidologie 2002, 33, 339-351. [CrossRef]

43. Stoltz, D.; Shen, X.R.; Boggis, C.; Sisson, G. Molecular diagnosis of Kashmir bee virus infection. J. Apic. Res. 1995, 34, 153-160. [CrossRef]

44. Singh, R.; Levitt, A.L.; Rajotte, E.G.; Holmes, E.C.; Ostiguy, N.; Vanengelsdorp, D.; Lipkin, W.I.; Depamphilis, C.W.; Toth, A.L.; Cox-Foster, D.L. RNA viruses in hymenopteran pollinators: Evidence of inter-Taxa virus transmission via pollen and potential impact on non-Apis hymenopteran species. PLoS ONE 2010, 5, e14357. [CrossRef]

45. Fu, Z.M.; Zhou, D.D.; Chen, H.Z.; Geng, S.H.; Chen, D.F.; Zheng, Y.Z.; Xiong, C.L.; Xu, G.J.; Zhang, X.; Guo, R. Analysis of highly expressed genes in Apis cerana cerana workers' midguts responding to Nosema ceranae stress. J. Sichuan Univ. (Nat. Sci. Ed.) 2020, 57, 191-198.

46. Forsgren, E.; Fries, I. Comparative virulence of Nosema ceranae and Nosema apis in individual European honey bees. Vet. Parasitol. 2010, 170, 212-217; [CrossRef]

47. Chen, D.; Chen, H.; Du, Y.; Zhou, D.; Geng, S.; Wang, H.; Wan, J.; Xiong, C.; Zheng, Y.; Guo, R. Genome-wide identification of long non-coding RNAs and their regulatory networks involved in Apis mellifera ligustica response to Nosema ceranae infection. Insects 2019, 10, 245. [CrossRef] [PubMed]

48. Langmead, B.; Salzberg, S.L. Fast gapped-read alignment with Bowtie 2. Nat. Methods 2012, 9, 357-359. [CrossRef]

49. Kim, D.; Pertea, G.; Trapnell, C.; Pimentel, H.; Kelley, R.; Salzberg, S.L. TopHat2: Accurate alignment of transcriptomes in the presence of insertions, deletions and gene fusions. Genome Biol. 2013, 14, R36. [CrossRef] [PubMed] 
50. Lu, X.; Kim, H.; Zhong, S.; Chen, H.; Hu, Z.; Zhou, B. De novo transcriptome assembly for rudimentary leaves in Litchi chinesis Sonn. and identification of differentially expressed genes in response to reactive oxygen species. BMC Genom. 2014, 15, 805. [CrossRef]

51. Ye, J.; Fang, L.; Zheng, H.; Zhang, Y.; Chen, J.; Zhang, Z.; Wang, J.; Li, S.; Li, R.; Bolund, L.; et al. WEGO: A web tool for plotting GO annotations. Nucleic Acids Res. 2006, 34, W293-W297. [CrossRef]

52. Du, Y.; Zhou, D.D.; Wan, J.Q.; Lu, J.X.; Fan, X.X.; Fan, Y.C.; Chen, H.; Xiong, C.L.; Zheng, Y.Z.; Fu, Z.M.; et al. Profiling and regulation network of differentially expressed genes during the development process of Apis mellifera ligustica worker's midgut. Sci. Agric. Sin. 2020, 53, 201-212.

53. Su, G.; Morris, J.H.; Demchak, B.; Bader, G.D. Biological network exploration with Cytoscape 3. Curr. Protoc. Bioinform. 2014, 47, 8-13. [CrossRef]

54. Livak, K.J.; Schmittgen, T.D. Anaysis of relative gene expression data using realtime quantitative PCR and the $2^{-\Delta \Delta C t}$ method. Methods 2001, 25, 402-408. [CrossRef]

55. Huang, Q.; Chen, Y.P.; Wang, R.W.; Cheng, S.; Evans, J.D. Host-parasite interactions and purifying selection in a microsporidian parasite of honey bees. PLoS ONE 2016, 11, e0147549. [CrossRef] [PubMed]

56. Huang, W.F.; Solter, L.F. Comparative development and tissue tropism of Nosema apis and Nosema ceranae. J. Invertebr. Pathol. 2013, 113, 35-41. [CrossRef]

57. Higes, M.; García-Palencia, P.; Martín-Hernández, R.; Meana, A. Experimental infection of Apis mellifera honeybees with Nosema ceranae (Microsporidia). J. Invertebr. Pathol. 2007, 94, 211-217. [CrossRef] [PubMed]

58. Vidau, C.; Panek, J.; Texier, C.; Biron, D.G.; Belzunces, L.P.; Le Gall, M.; Broussard, C.; Delbac, F.; El Alaoui, H. Differential proteomic analysis of midguts from Nosema ceranae-infected honeybees reveals manipulation of key host functions. J. Invertebr. Pathol. 2014, 121, 89-96. [CrossRef]

59. Panek, J.; Paris, L.; Roriz, D.; Mone, A.; Dubuffet, A.; Delbac, F.; Diogon, M.; El Alaoui, H. Impact of the microsporidian Nosema ceranae on the gut epithelium renewal of the honeybee, Apis mellifera. J. Invertebr. Pathol. 2018, 159, 121-128. [CrossRef] [PubMed]

60. Evans, J.D.; Aronstein, K.; Chen, Y.P.; Hetru, C.; Imler, J.L.; Jiang, H.; Kanost, M.; Thompson, G.J.; Zou, Z.; Hultmark, D. Immune pathways and defence mechanisms in honey bees Apis mellifera. Insect Mol. Biol. 2006, 15, 645-656. [CrossRef]

61. Govind, S. Innate immunity in Drosophila: Pathogens and pathways. Insect Sci. 2008, 15, 29-43. [CrossRef]

62. Aronstein, K.A.; Murray, K.D. Chalkbrood disease in honey bees. J. Invertebr. Pathol. 2010, 103, S20-S29. [CrossRef]

63. Glinski, Z.; Jarosz, J. Infection and immunity in the honey bee Apis mellifera. Apiacta 2001, 36, 12-24.

64. Glinski, Z.; Buczek, K. Response of the Apoidea to fungal infections. Apiacta 2003, 38, 183-189.

65. Xu, Z.; Zhu, L.; Yang, Y.; Zhang, Y.; Lu, M.; Tao, L.; Xu, W. Bifenthrin induces DNA damage and autophagy in Spodoptera frugiperda (Sf9) insect cells. In Vitro Cell. Dev. Biol. Anim. 2021, 57, 264-271. [CrossRef] [PubMed]

66. He, C.; Klionsky, D.J. Regulation mechanisms and signaling pathways of autophagy. Annu. Rev. Genet. 2009, 43, 67-93. [CrossRef]

67. Nakagawa, I.; Amano, A.; Mizushima, N.; Yamamoto, A.; Yamaguchi, H.; Kamimoto, T.; Nara, A.; Funao, J.; Nakata, M.; Tsuda, K.; et al. Autophagy defends cells against invading group a Streptococcus. Science 2004, 306, 1037-1040. [CrossRef]

68. Orvedahl, A.; MacPherson, S.; Sumpter, R.J.; Tallóczy, Z.; Zou, Z.; Levine, B. Autophagy protects against Sindbis virus infection of the central nervous system. Cell Host Microbe. 2010, 7, 115-127. [CrossRef]

69. Shelly, S.; Lukinova, N.; Bambina, S.; Berman, A.; Cherry, S. Autophagy is an essential component of Drosophila immunity against vesicular stomatitis virus. Immunity 2009, 30, 588-598. [CrossRef]

70. Moy, R.H.; Cherry, S. Antimicrobial autophagy: A conserved innate immune response in Drosophila. J. Innate. Immun. 2013, 5, 444-455. [CrossRef] [PubMed]

71. Eng, M.W.; van Zuylen, M.N.; Severson, D.W. Apoptosis-related genes control autophagy and influence DENV-2 infection in the mosquito vector, Aedes aegypti. Insect Biochem. Mol. Biol. 2016, 76, 70-83. [CrossRef] [PubMed]

72. Paulus, G.L.; Xavier, R.J. Autophagy and checkpoints for intracellular pathogen defense. Curr. Opin. Gastroenterol. 2015, 31, 14-23. [CrossRef] [PubMed]

73. Choi, Y.; Bowman, J.W.; Jung, J.U. Autophagy during viral infection-a double-edged sword. Nat. Rev. Microbiol. 2018, 16, 341-354. [CrossRef]

74. McBride, W.H.; Iwamoto, K.S.; Syljuasen, R.; Pervan, M.; Pajonk, F. The role of the ubiquitin/proteasome system in cellular responses to radiation. Oncogene 2003, 22, 5755-5773. [CrossRef]

75. Kurze, C.; Mayack, C.; Hirche, F.; Stangl, G.I.; Le Conte, Y.; Kryger, P.; Moritz, R.F. Nosema spp. infections cause no energetic stress in tolerant honeybees. Parasitol. Res. 2016, 115, 2381-2388. [CrossRef]

76. Dussaubat, C.; Maisonnasse, A.; Crauser, D.; Beslay, D.; Costagliola, G.; Soubeyrand, S.; Kretzchmar, A.; Le Conte, Y. Flight behavior and pheromone changes associated to Nosema ceranae infection of honey bee workers (Apis mellifera) in field conditions. J. Invertebr. Pathol. 2013, 113, 42-51. [CrossRef] [PubMed]

77. Wolf, S.; McMahon, D.P.; Lim, K.S.; Pull, C.D.; Clark, S.J.; Paxton, R.J.; Osborne, J.L. So near and yet so far: Harmonic radar reveals reduced homing ability of Nosema infected honeybees. PLoS ONE 2014, 9, e103989. [CrossRef]

78. Kaur, G.; Iyer, L.M.; Burroughs, A.M.; Aravind, L. Bacterial death and TRADD-N domains help define novel apoptosis and immunity mechanisms shared by prokaryotes and metazoans. Elife 2021, 10, e70394. [CrossRef]

79. Narayan, K. Insect defence: Its impact on microbial control of insect pests. Curr. Sci. 2004, 86, 800-814. 
80. Guo, R.; Chen, D.; Diao, Q.; Xiong, C.; Zheng, Y.; Hou, C. Transcriptomic investigation of immune responses of the Apis cerana cerana larval gut infected by Ascosphaera apis. J. Invertebr. Pathol. 2019, 166, 107210. [CrossRef]

81. Stanley, D.; Miller, J.; Tunaz, H. Eicosanoid actions in insect immunity. J. Innate. Immun. 2009, 1, 282-290. [CrossRef]

82. Yeh, J.X.; Park, E.; Schultz, K.L.W.; Griffin, D.E. NF- $\kappa$ B activation promotes alphavirus replication in mature neurons. J. Virol. 2019, 93, e01071-19. [CrossRef]

83. Hayden, M.S.; Ghosh, S. NF- $\kappa$ B, the first quarter-century: Remarkable progress and outstanding questions. Genes Dev. 2012, 26, 203-234. [CrossRef] [PubMed]

84. Khor, S.; Cai, D. Control of lifespan and survival by Drosophila NF- $\kappa$ B signaling through neuroendocrine cells and neuroblasts. Aging (Albany NY) 2020, 12, 24604-24622. [CrossRef] [PubMed]

85. Valanne, S.; Wang, J.H.; Rämet, M. The Drosophila Toll signaling pathway. J. Immunol. 2011, 186, 649-656. [CrossRef]

86. Myllymäki, H.; Valanne, S.; Rämet, M. The Drosophila imd signaling pathway. J. Immunol. 2014, 192, 3455-3462. [CrossRef] [PubMed]

87. Hoffmann, J.A.; Reichhart, J.M. Drosophila innate immunity: An evolutionary perspective. Nat. Immunol. 2002, 3, 121-126. [CrossRef]

88. De Gregorio, E.; Spellman, P.T.; Tzou, P.; Rubin, G.M.; Lemaitre, B. The Toll and Imd pathways are the major regulators of the immune response in Drosophila. EMBO J. 2002, 21, 2568-2579. [CrossRef]

89. Tanji, T.; Hu, X.; Weber, A.N.; Ip, Y.T. Toll and IMD pathways synergistically activate an innate immune response in Drosophila melanogaster. Mol. Cell. Biol. 2007, 27, 4578-4588. [CrossRef]

90. Lin, C.C.; Chou, C.M.; Hsu, Y.L.; Lien, J.C.; Wang, Y.M.; Chen, S.T.; Tsai, S.C.; Hsiao, P.W.; Huang, C.J. Characterization of two mosquito STATs, AaSTAT and CtSTAT. Differential regulation of tyrosine phosphorylation and DNA binding activity by lipopolysaccharide treatment and by Japanese encephalitis virus infection. J. Biol. Chem. 2004, 279, 3308-3317. [CrossRef] [PubMed]

91. Zhang, X.; Guo, R.; Kumar, D.; Ma, H.; Liu, J.; Hu, X.; Cao, G.; Xue, R.; Gong, C. Identification gene expression and immune function of the novel Bm-STAT gene in virus-infected Bombyx mori. Gene 2016, 577, 82-88. [CrossRef] [PubMed]

92. Dostert, C.; Jouanguy, E.; Irving, P.; Troxler, L.; Galiana-Arnoux, D.; Hetru, C.; Hoffmann, J.A.; Imler, J.L. The Jak-STAT signaling pathway is required but not sufficient for the antiviral response of drosophila. Nat. Immunol. 2005, 6, 946-953. [CrossRef] [PubMed]

93. Agaisse, H.; Petersen, U.M.; Boutros, M.; Mathey-Prevot, B.; Perrimon, N. Signaling role of hemocytes in Drosophila JAK/STATdependent response to septic injury. Dev. Cell 2003, 5, 441-450. [CrossRef] 